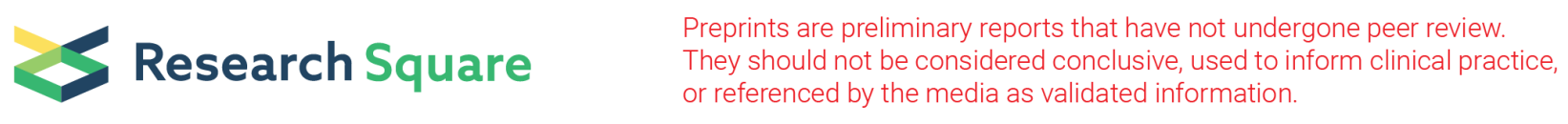

\title{
Computational proteomics analysis reveals pathogen secreted carbohydrate active enzymes in tomato xylem sap
}

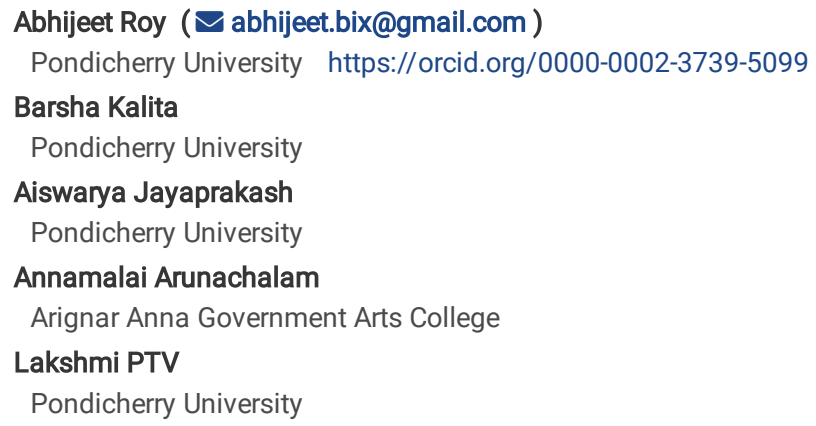




\section{Abstract}

Fusarium oxysporum f. sp. lycopersici (Fol), a causal organism of Fusarium wilt in the tomato plant, secretes cell wall degrading enzymes, also known as carbohydrate-active enzymes (CAZymes). These are crucial during colonization and pathogenesis, as evidenced by several proteomic studies, revealing the importance of these CAZymes in virulence and pathogenicity. However, few of them have been done in-planta, exhibiting differences in the expression of these cell wall degrading enzymes compared to in-vitro studies. Therefore, to explore the CAZymes involved in pathogenesis while residing in the host plant, an inplanta (xylem sap) proteomics of a susceptible tomato variety affected with Fol was done. Most of these CAZymes belonged to the hydrolase and oxidoreductase families having no significant homology with tomato proteins. Nearly $90 \%$ of them were predicted to be soluble and extracellular. The core CAZymes families with interactional evidence identified were AA3, GH3, GH18, GH20, GH28, GH43, GH47, GH55 and CE8. Thus, apart from annotating some of the hypothetical proteins to be CAZymes, the study sheds light on CAZymes families that may have a role in the pathogenesis and survival of this fungus in the susceptible tomato plant.

\section{Introduction}

Fusarium oxysporum species complex (FOSC) causing wilt and rot disease in various plant species is generally host-specific and known as formae speciales, ff. spp. (singular formae specialis, f. sp.). These plant pathogenic formae speciales follow a similar infection mechanism in the host plant, which includes penetration through root and colonization in the xylary tract (Lagopodi et al. 2002; Jiménez-Fernández et al. 2013; Lu et al. 2013; Upasani et al. 2016; Dong et al. 2019), resulting in wilting in some cases, root rot of susceptible plants leading to necrosis. One such formae specialis is f. sp. lycopersici, affecting the important vegetable crop tomato grown worldwide (http://www.fao.org/faostat/en/\#data/QC/visualize).

To penetrate the root for successful colonization, $\mathrm{f}$. sp. lycopersici requires crossing the cell wall barrier of the host plant. These cell wall barriers are composed of cellulose, hemicellulose, pectin, lignin, and other proteins, essentially present for structural integrity (Rose et al. 2004; Cosgrove 2005). The process of cell wall deconstruction by the pathogen is achieved by the enzymes known as plant cell wall degrading enzymes (PCWDE), which within the host plants help degrade the plant tissues for liberating mono- and oligosaccharides required for their growth (Kubicek et al. 2014). Some of these enzymes are also needed for cell wall remodeling (Beauvais and Latgé 2018) and at the later stage of colonization (Gibson et al. 2011). These CWDEs are a subset of enzyme families know as Carbohydrate active enzymes (CAZymes), which according to the CAZy database (http://www.cazy.org/) (Lombard et al. 2014), are divided into five modules, i.e., Auxiliary activities (AA), carbohydrate Esterase (CE), Glycosyl Hydrolase (GH), Glycosyl Transferase (GT), Polysaccharide Lyase $(\mathrm{PL})$ and one associated module, Carbohydrate-Binding Modules (CBM), consisting of several families based on functional, structural and sequence similarities. The families in these modules are further divided into four broad categories based on their activities, such as cellulose-degrading (mostly $\mathrm{GH}$ family), hemicellulose degrading (GH and $\mathrm{CE}$ ), pectin ( $\mathrm{GH}, \mathrm{CE}$, and $\mathrm{PL}$ ) and lignin-degrading (mostly $\mathrm{AA})$. In contrast, members of the $\mathrm{GT}$ family are involved in the biosynthetic process. The FOSC and other sordariomycetes harbor a plethora of CAZymes in their genome

(https://mycocosm.jgi.doe.gov/mycocosm/annotations/browser/cazy/summary;85ATbn?p=dothideomycetes) with a majority of them belonging to GH families followed by GT, AA, CE, PL and being necrotrophic, codes for a significant amount of PCWDE as well as secretory CAZymes in Fusarium oxysporum formae speciales (Roy et al. 2020).

Over the last decade, fungal proteomics have taken the lead in the field of omics due to the availability of full-length fungal genomes, high throughput transcriptomic data and advancements in protein mass spectrometry, which gave us a valuable insight into the pathogenicity of the plant fungal pathogens. Although proteomics analysis of host plants in response to Fusarium oxyporum formae speciales, such as banana (Li et al. 2013; Lu et al. 2013; Dong et al. 2019), cabbage (Pu et al. 2016), cucumber (Zhang et al. 2016), pea (Castillejo et al. 2015), tomato (Gawehns et al. 2015; Silva et al. 2017; de Lamo et al. 2018) and strawberry (Fang et al. 2013) have been done, but several proteomics studies were also performed in Fusarium species, including the Fusarium oxysporum ff. spp. For instance, an exoproteome study on Fusarium graminearum grown on the cell wall of Humulus lupulus L. (Phalip et al. 2005) revealed Cellobiohydrolase (belonging to GH6 and GH48) to be pre-dominant in pathogen-plant interaction. Similarly, in a study (Paper et al. 2007) on the same fungal species, in-planta and in-vitro analyses evidenced the presence of hydrolase, lyase, and esterase in the former, suggesting their role in pathogenesis. Likewise, another study on Fusarium proliferatum also showed inhibition of CWDEs consisting of glucanase, cellulase, and glucanosyltransferase (Li et al. 2017) to be influenced by high $\mathrm{pH}$, therefore affecting its growth.

Among the F. oxysporum $\mathrm{ff} s p$., an in vitro comparative proteomics studies on the races of $\mathrm{f}$. $\mathrm{sp}$. cubense and f. sp. conglutinans enabled the identification of proteins involved in carbohydrate metabolism, in which chitinase and a-galactosidase were revealed to be differentiating the virulence pattern in former (Sun et al. 2014), whereas the glycosidase protein was observed to differ among the races of the latter (Li et al. 2015). Moreover, some CWDE in $\mathrm{f}$. sp. cubense, such as glucanase and cellobiose dehydrogenase, were found to be downregulated by deleting a transcription factor resulting in the reduction of the pathogenicity (Hou et al. 2018). Simultaneously, some cell wall modifying enzymes were also expressed during conidial germination (Deng et al. 2015), depicting their role in growth. Likewise, another comparative proteomics analysis of different isolates of $\mathrm{f}$. $\mathrm{sp}$. lycopersici revealed the importance of endo- $\beta$ - $\mathrm{N}$ acetylglucosaminidases (GH85) in imparting the virulence (Manikandan et al. 2018). Although most proteomics work is done so far to identify and decipher the role of cell wall degrading enzymes has been through in-vitro studies. Still, very few of them were reported in-planta using Fusarium species. Concerning the formae speciales, any study reported so far was only on $f$. sp. lycopersici assessing the pathogenicity of chromosomes (Schmidt et al. 2013). Thus, to narrow down this gap with the process of annotating and implicating the role of CAZymes in pathogenesis, a downstream proteomics analysis was done using publically available proteomics data of tomato xylem sap infected with Fusarium oxysporum f. sp. lycopersici. Further, using computational tools to substantiate the importance of these cell wall degrading enzymes which would otherwise may not be expressed at the protein level under in-vitro conditions in this pathogenic fungus.

\section{Material And Methods}




\section{Data retrieval}

The LTQ Orbitrap label-free mass spectrometric publically available data of tomato xylem sap with accession: PXD011072

(https://www.ebi.ac.uk/pride/archive/projects/PXD011072) was downloaded from PRIDE (https://www.ebi.ac.uk/pride/) which constituted the experiments performed elsewhere (Gawehns et al. 2015; de Lamo et al. 2018). This study includes a differential proteomics analysis of a resistant and susceptible tomato variety infected with F.oxysporum f. sp. lycopersici (Fol). Samples consisting of a susceptible host infected with Fol and a mock treated of the same tomato cultivar were taken for further analysis, based on the hypothesis proposed in the current study. A total of eight samples, i.e., four replicates each (FR24 to FR27) considered as treated (T) and (FR12 to FR15) considered as mock treated (M) in PXD011072 were taken. These experiments were done in a climate controlled greenhouse at $25^{\circ} \mathrm{C}$ with a relative humidity of $65 \%$ and 16 hours photoperiod. The pathogen used was Fol race 1 (fol007) and the susceptible tomato plant cultivar C32. Protein sequences of the organisms Tomato (Solanum lycopersicum assembly SL3.0) consisting of 37660 proteins and Fusarium oxysporum (Fusarium oxysporum f. sp. lycopersici 4287 assembly ASM14995v2) consisting of 27347 proteins were downloaded from NCBI (https://www.ncbi.nlm.nih.gov/genome/) database.

\section{Data processing}

All the raw files of a susceptible plant treated with Fol and mock treated were processed in the MaxQuant version 1.6.17.0 (Tyanova et al. $2016 a$ ) for protein identification using an inbuilt search engine against the protein database created by taking Fol and tomato proteins mentioned above with an in-built contaminant database (246 proteins). Label-free quantification was done using default parameters (Cox et al. 2011, 2014) with a match between runs enabled and label-free quantification (LFQ) minimum ratio count set to 1. An extra variable modification- deamidation (NQ), performed by original authors (de Lamo et al. 2018) was also included for the protein quantification. The data generated were further filtered and analyzed on Perseus 1.6.14.0 (Tyanova et al. $2016 \mathrm{~b}$ ), where all the peptide counts less than 2 identifying a protein group were filtered out. The LFQ intensities were further Log $\log _{2}(\mathrm{x})$ transformed to visualize the data. The proteins identified in the tomato were removed for subsequent analysis retaining the proteins identified by at least one unique and one unmodified peptide for the Fol proteins.

\section{Gene Ontology (GO) analysis}

The Fol proteins identified in the xylem sap were subjected to gene ontologies (GO) annotation using Blast2G0 5.2.5 suite (Götz et al. 2008) with an in-built InterPro tool by keeping default settings to see the categorical representation of these proteins in individual studies. The proteins with $\mathrm{GO}$ annotations were further visualized using WEGO 2.0 (http://wego.genomics.org.cn/) (Ye et al. 2018) for the Fol proteins identified in the experiment. Additionally, GO term enrichment analysis was also performed to visualize the functional enrichment using web-based tool g: Profiler (https://biit.cs.ut.ee/gprofiler/gost) (Raudvere et al. 2019) after selecting the organism Fusarium oxysporum f. sp. lycopersici and with the default options for the enrichment process.

\section{Carbohydrate-active enzymes (CAZymes) annotation}

A web-based meta server as well as a stand-alone tool- dbCAN2 (http://bcb.unl.edu/dbCAN2/index.php) (Zhang et al. 2018) was used to annotate the CAZymes among the identified protein groups in Fol. This web-based meta server annotates CAZymes using three integrated search tools, HMMER (http://hmmer.org/), DIAMOND (https://github.com/bbuchfink/diamond) and HotPep (Busk et al. 2017) for the annotation of CAZymes with their default parameters from the search databases viz. dbCAN, CAZy and PPR databases, respectively. This meta server tool suggests retaining only those CAZymes, which are annotated with a minimum of 2 integrated tools for better prediction confidence.

\section{Secretory protein and subcellular localization analysis}

As the xylem sap collected in these datasets were devoid of any physical presence of fungus. Therefore, to ascertain if CAZymes annotated in the identified Fol proteins were secretory or extracellular in origin, two online tools, namely, SignalP 5.0 (http://www.cbs.dtu.dk/services/SignalP/) (Almagro Armenteros et al. 2019) and DeepLoc 1.0 (http://www.cbs.dtu.dk/services/DeepLoc/) (Almagro Armenteros et al. 2017), were used. These two tools work on deep- and recurrent- neural network approaches, respectively. The former predicted the signal peptides by keeping the organism group- Eukarya, and the latter identified the subcellular localization by keeping PROFILES as a protein-coding option for accurate prediction.

\section{Metabolic pathway enrichment and ortholog interaction network analysis}

The CAZymes identified were analyzed for their chromosomal location by taking the respective gene accessions of the identified CAzymes through the genome view option and metabolic pathways enrichment was also done with a p-value $<0.05$ using FungiDB (https://fungidb.org/fungidb/app) (Basenko et al. 2018). Further, an evidence-based protein interaction network was analyzed using STRING 11.0 (https://string-db.org/) (Szklarczyk et al. 2019) by taking clusters of orthologous groups (COG), Eukaryotic orthologous group (KOG) and non-supervised orthologous groups (NOG) for the corresponding CAZymes families with the settings: minimum required interaction score of 0.700 (high confidence) and a maximum number of five interactors in the first shell to see the existing interaction among these ortholog groups of the identified CAZymes.

\section{Results}

\section{Identification of protein groups and statistical analysis}

The proteins identified in the individual sample dataset after filtering (i.e., the removal of contaminants, reverse hits, and proteins identified only by site) revealed the number of proteins identified in tomato and Fol is summarized in Table 1. The $\log _{2}(x)$ transformed LFQ intensities were plotted for each of the experiments (Fig.1) with an average mean of 22.6 and 20.0, median of 22.4 and 19.8 in all the four replicates of treated (T) and mock (M), respectively 
(Supplementary Table 1). The histogram revealed the data to be more or less normally distributed. These replicates showed a Pearson correlation of more than 0.8 in both mock and treated samples (Fig. 2).

\section{Functional assessment of Fol proteins}

All the Fol proteins identified in the susceptible tomato plant have proceeded for $\mathrm{GO}$ annotation. A total of 36 out of 53 protein accessions were assigned for some $\mathrm{GO}$ terms. Among these $\mathrm{GO}$ terms, $32 \mathrm{GO}$ terms were assigned for biological functions, whereas $36 \mathrm{GO}$ terms were assigned to some molecular functions with $3 \mathrm{GO}$ terms belonging to cellular functions. The histogram of $\mathrm{GO}$ categories revealed the majority of the $\mathrm{GO}$ categories were involved in primary and organic substance metabolic processes followed by the oxidation-reduction process with a function of hydrolase and oxidoreductase activity (Fig. 3a).

In gene enrichment analysis, the proteins in each experiment were assigned to their respective gene accessions. The enrichment analysis using g:SCS threshold, which is an algorithm developed by the authors of the tool utilized for multiple testing correction, revealed the enriched biological process to be carbohydrate metabolic process (GO: 0005975) and response to oxidative stress (G0: 0006979) with most significant molecular functions of hydrolase activity (GO: 0016798, G0: 0004553, G0:0016787), polygalacturonase activity (G0:0004650) catalase activity (G0:0004096), peroxidase activity (G0:0004601), oxidoreductase activity (G0:0016684), antioxidant activity (G0:0016209) and catalytic activity(G0:0003824) (Fig. 3b).

\section{Annotated and core CAZymes in Fol proteins}

After filtering the CAZymes annotated by $>=2$ tools from dbCAN2 annotation results (Fig. 4; Supplementary Table 2), altogether, 30 protein accessions were annotated as CAZymes. Most of the CAZymes belonged to the families of GH, followed by AA and only one CE family, i.e., CE8 (Table 2). Among these protein accessions annotated for CAZymes, 16 of them were hypothetical proteins (HP). Further, the GO annotation from the already annotated protein groups in the previous step revealed 24 protein accessions coding for CAZymes families were having GO terms associated with them (Supplementary Table 3 ). Interestingly, most GO categories were identified to be involved in primary and organic substance metabolic processes having hydrolase and oxidoreductase activities.

\section{Secreted protein and subcellular localization of identified CAZymes}

To confirm the CAZymes identified above belonged to secretory proteins and extracellular in function, which apparently may influence the process of pathogenesis and colonization after infecting the host plant, they were subjected to secretory protein analysis. Interestingly, nearly $90 \%$ of the CAZymes were found to have standard signal peptides cleaved by signal peptidase I (Table 2, Supplementary Table 4 and 5) and extracellular in nature except for GH47 and $\mathrm{GH} 72$, though harboring signal peptide. Most of these extracellular CAZymes combined together were generally hemicellulose degrading (GH18, GH20, GH43, $\mathrm{GH} 93, \mathrm{GH} 32)$, followed by cellulose/hemicellulose degradation ( $\mathrm{GH} 45, \mathrm{GH} 3)$, oxidoreductase (AA3, AA5) and pectin degrading (CE8, GH28).

\section{Chromosomal location, metabolic pathway enrichment and interaction network of CAZymes}

The CAZymes identified were found to be located on chromosome 1, 3, 4, 5, 6, 7, 8, 10, 11, 12, 13 and 14 (Table 3), with half of them to be located on the reverse strand. In the metabolic enrichment process, the pathway in which these CAZymes involved were pectin degradation (CE8 and GH28), choline degradation (AA3_2) and chitin degradation (GH18, GH20, GH45, GH47) with a p-value from Fisher's exact test, Bonferroni adjusted p-value $\mathrm{n}$ and Benjamini Hochberg false discovery rate (FDR) cut-off $<0.05$ (Supplementary Table 6). The CAZymes families were further studied for an evidence-based interactional network to elucidate a relationship among these CAZymes present in xylem sap of the host plant infected with pathogen Fol. Hence, an interaction network of ortholog groups, COG, KOG and NOG corresponding to the gene accessions of each protein group was created, which resulted in 7 CAZymes families encompassing 12 protein accessions (Table 4) having direct and indirect interaction within them. The interaction network with a combined interaction score ranged from 0.7-0.9 (Supplementary Table 7) and revealed six of the CAZymes families, i.e., GH3, GH18, GH20, GH28, GH43 and CE8, having direct interaction evidence. In contrast, AA3 linked with GH18 through an enzyme Acyl-CoA reductase (COG1012), GH3 linked with GH18 through pectate lyase (COG3866), GH32 and GH55 were connected through a glucanase (GH17 family, COG5309) whereas, GH74 was interlinked with a mannosidase (KOG2204) and a transferase (KOG1413), revealed to be involved in the polysaccharide degrading process (Fig. 5).

\section{Discussion}

The plant pathogen Fusarium oxysporum f. sp. lycopersici, a causal organism of tomato wilt, like many other members of FOSC, follows the same mechanism of entry and colonization process in the xylem before the wilting of plants takes place. For the successful infection and colonization in the host plants, a complex and coordinated interplay of enzymes is required, including cell wall degrading enzymes, which probably act as key players in the pathogenesis and growth. A difference in the proteins was found among the data taken, i.e., presence of proteins in the treated compared to mock samples, especially the proteins belonging to hydrolase and oxidoreductase families and the activities of these enzymes had shed light on the mechanism of infection while inside the host plant as also reported in case of Fusarium graminearum (Paper et al. 2007). Further, the carbohydrate metabolism process was found significant with hydrolase and oxidoreductase activity, reflecting the importance of these CAZYmes during the pathogenesis.

Perhaps, most of the CAZymes annotated in the Fol proteins were described as hypothetical proteins (HP); therefore, the functional assignment to these HP was also achieved in the present study. Interestingly, the CAZymes identified, such as AA3 (Schmidt et al. 2013), belonged to gene accessions that were present on conditionally dispensable chromosomes (CDC), also known as supernumerary chromosomes (SC) or lineage-specific (LS) chromosomes, though not on Fol CDC but GH3 and GH43 were reported to be present on legume infecting formae speciales CDC (Williams et al. 2016). These chromosomes are known to determine the pathogenicity in Fusarium oxysporum formae speciales (Ma et al. 2010; Vlaardingerbroek et al. 2016; Williams et al. 2016; van Dam et al. 2017). At the same time, the majority of CAZymes were predicted to be soluble and extracellular proteins involved in the degradation of polysaccharides, either of plant or fungal origin. However, two CAZymes families: GH47 (alpha-mannosidase) and GH72 ( $\beta$-1,3-glucanosyl transglycosylase), were membrane proteins harboring signal peptides. 
Among these non-secretory CAZymes, GH72 ( $\beta$-1,3-glucanosyl transglycosylase), a membrane protein, was revealed to help in fungal cell wall formation and attachment of glycoprotein into the cell wall (Ao and Free 2017; Kar et al. 2019). Likewise, another membrane protein, GH47 (a-mannosidase) was also reported to be involved in cell wall morphogenesis with a secretory CAZyme GH20 ( $\beta$-hexosaminidase) (Wymelenberg et al. 2010). However, not being extracellular but the presence of these CAZymes in the xylem sap suggest them to be important in fungal growth and survival while inside the plant.

The secretory CAZymes reported to be involved in fungal cell wall degradation, GH55 ( $\beta$-1,3-glucanase) seemed to have a role in cell wall morphogenesis and germination (Millet et al. 2019). Moreover, an important family and much explored CAZyme, GH18 (Chitinase), identified in the present study signified its role in morphogenesis, defence, or parasitism (Oyeleye and Normi 2018) because of its involvement in the breakdown of chitin, an essential component of the fungal cell wall for cell growth and plasticity (Langner et al. 2015). Further, the presence of these two CAZymes viz. GH55 and GH18 were also reported to be found in the secretome of Aspergillus niger (Nitsche et al. 2012). Meanwhile, the GH families, especially GH20 ( $\beta$ - hexosaminidase), was reported to be involved in the trans-glycosylation process (Muschiol et al. 2020) and helps in fungal hyphal growth and branching (Rast et al. 1991). Additionally, the role of this family had also been shown to assist the chitinase for the complete degradation of chitin (López-Mondéjar et al. 2009). Moreover, the family GH32 (invertase) involved in the hydrolysis of sucrose reported here, perhaps, indicated its significant role in an increased level of pathogenicity (Ruiz and Ruffner 2002; Voegele et al. 2006). However, its actual role in plant-pathogen interaction remains unclear (Chang et al. 2017).

Further, the rest of the extracellular CAZymes, including AA3, an aryl-alcohol or glucose oxidases, was identified to play a role in biomass degradation as in the case of a necrotrophic fungus, Botrytis cinerea (Petrasch et al. 2019). Likewise, AA5 (a galactose, raffinose or alcohol oxidase) that oxidize oligogalacturonides simultaneously was reported to reduce the activation of plant immune response(Ferrari et al. 2013).

Pectinolytic enzymes are very crucial in the process of pathogenesis because of their role in plant cell wall degradation and the CAZyme, CE8 (pectin methylesterase), the only CE family identified with $\mathrm{GH} 28$ (polygalacturonase) was identified to be involved in pectin degradation by a de-esterification process, which in turn, allows the pectin accessible to other pectinases such as polygalacturonase (Pelloux et al. 2007), while GH28 was reported to be engaged in the breaking of a-linked galacturonic acid bonds (Markovič and Janeček 2001) in the pectin. Moreover, the presence of these two CAZymes families was also reported to be co-expressed in a basidiomycetes fungus (Miyauchi et al. 2016) and identified in the secretome of an ascomycetes species (Couturier 2016). Other CWDEs, GH3 ( $\beta$-glucosidase), reported having a role in chitinolytic activity (Yang et al. 2014) was observed to be involved in cellulose as well as hemicellulose degradation. Further, the coordinated effort of hemicellulose degrading CAZymes GH43( $\beta$-xylosidase) and GH93( $\alpha$-arabinanase) was also reported in Aspergillus fumigatus (de Gouvêa et al. 2018).

To get an insight into the coordination of these CAZymes, an interaction network of the CAZymes based on the evidence from various sources resulted in the identification of six CAZymes, i.e., GH3, GH18, GH20, GH28, GH43 and CE8 to be directly involved in the interactions out of which excluding GH3, the other CAZymes were enriched for a metabolic pathway involved in pectin and chitin degradation. Although enriched for and belonging to different cell wall degrading categories, i.e., cellulose/hemicellulose, hemicellulose and pectin, their coordination might be playing a significant role in fungal growth and pathogenesis. Besides this, GH3 also possessing chitinolytic activity and interacting with GH18, may involve in the chitin degrading mechanism (Yang et al. 2014), suggesting their significant role in the process of morphogenesis of the fungus. Meanwhile, their interconnected network, along with the contribution of CE8, which also assist other polygalacturonases, is found to be interacting with a pectate lyase and a xylosidase, where both of these families in a broad sense considered as plant cell wall degrading enzymes. Therefore, the coordination of these CAZymes in the network (including GH43, hemicellulose degrading CAZymes) and their presence in the xylem sap implicates a role in fungal colonization, most probably by degrading complex sugars into simpler sugar forms for growth and morphogenesis. Another CAZymes, i.e., GH55, although not directly reported to be involved in the main network, but was observed to be linked with a GH17 family, perhaps contributing to the phenomenon of cell morphogenesis and conidiation (Millet et al. 2018, 2019), which is further connected to GH32 (invertase), an enzyme involves in breaking down of sucrose sugar abundantly found in plants.

Hence, within the intricate mechanism of cell wall degradation during the process of colonization by this fungus, some of the crucial CAZymes families, i.e., $\mathrm{AA} 3, \mathrm{GH} 3, \mathrm{GH} 18, \mathrm{GH} 20, \mathrm{GH} 28, \mathrm{GH} 43, \mathrm{GH} 55$ and $\mathrm{CE} 8$, were identified in the xylem sap of a susceptible host plant, which could be key players in the pathogenesis and also gave a glimpse on the mechanism of colonization among the interacting CAZymes through available evidence. Therefore, extracellular CAZymes identified in the xylem sap might have been involved in the growth, maintenance and colonization process of this pathogen.

\section{Conclusion}

Although several secretomes and transcriptomic studies in various pathogenic fungi were done, most of them were restricted to in-vitro set up only; hence an attempt was made to fulfil this lacuna. Therefore, to identify and annotate the cell wall degrading CAZymes at the protein level and revealing the role of these CAZymes in the process of successful pathogenesis through cell wall degradation and also in fungal survival, the present study of in-planta proteomics analysis of two independent data sets was done to elucidate cell wall degrading CAZymes families of fungal origin. Some of the families belonging to AA, CE and $\mathrm{GH}$ were identified and their potential role in fungal colonization and pathogenicity as understood was discussed. Hence, this study provides a future scope for detailed studies on these candidate CAZymes within the formae speciales and to depict their elaborate mechanisms during pathogenesis.

\section{Declarations}

\section{Acknowledgement}

All the authors are thankful to Centre for Bioinformatics, Pondicherry University, for providing the necessary facilities to carry out this research work. Mrs. Aiswarya Jayaprakash is availing fellowship as a senior research fellow from Bioinformatics National Certification (BINC), Department of Biotechnology (DBT), India. 


\section{Funding}

No funding was received for conducting this study.

\section{Conflicts of interest/Competing interests:}

The authors have no conflicts of interest to declare that are relevant to the content of this article.

\section{Availability of data and material}

All data generated or analysed during this study are included in this published article (and its supplementary information files)

\section{Code availability NA}

\section{Authors' contributions}

AR and PTV designed the study. AR BK and AJ performed the analysis. AR, BK, AA and PTV wrote the final manuscript. All the authors analyzed and approved the manuscript.

\section{Ethics approval NA}

\section{Consent to participate NA}

\section{Consent for publication NA}

\section{References}

Almagro Armenteros JJ, Sønderby CK, Sønderby SK, et al (2017) DeepLoc: prediction of protein subcellular localization using deep learning. Bioinformatics 33:3387-3395. https://doi.org/10.1093/bioinformatics/btx431

Almagro Armenteros JJ, Tsirigos KD, Sønderby CK, et al (2019) SignalP 5.0 improves signal peptide predictions using deep neural networks. Nat Biotechnol 37:420-423. https://doi.org/10.1038/s41587-019-0036-z

Ao J, Free SJ (2017) Genetic and biochemical characterization of the GH72 family of cell wall transglycosylases in Neurospora crassa. Fungal Genet Biol 101:46-54. https://doi.org/10.1016/j.fgb.2017.03.002

Basenko EY, Pulman JA, Shanmugasundram A, et al (2018) FungiDB: An Integrated Bioinformatic Resource for Fungi and Oomycetes. J Fungi 4:39. https://doi.org/10.3390/jof4010039

Beauvais A, Latgé J-P (2018) Special Issue: Fungal Cell Wall. J Fungi 4:91. https://doi.org/10.3390/jof4030091

Busk PK, Pilgaard B, Lezyk MJ, et al (2017) Homology to peptide pattern for annotation of carbohydrate-active enzymes and prediction of function. BMC Bioinformatics 18:214. https://doi.org/10.1186/s12859-017-1625-9

Castillejo MÁ, Bani M, Rubiales D (2015) Understanding pea resistance mechanisms in response to Fusarium oxysporum through proteomic analysis. Phytochemistry 115:44-58. https://doi.org/10.1016/j.phytochem.2015.01.009

Chang Q, Liu J, Lin X, et al (2017) A unique invertase is important for sugar absorption of an obligate biotrophic pathogen during infection. New Phytol 215:1548-1561. https://doi.org/10.1111/nph.14666

Cosgrove DJ (2005) Growth of the plant cell wall. Nat Rev Mol Cell Biol 6:850-861. https://doi.org/10.1038/nrm1746

Couturier M (2016) Fungal secretomics of ascomycete fungi for biotechnological applications. Mycosphere 7:1546-1553.

https://doi.org/10.5943/mycosphere/si/3b/6

Cox J, Hein MY, Luber CA, et al (2014) Accurate Proteome-wide Label-free Quantification by Delayed Normalization and Maximal Peptide Ratio Extraction, Termed MaxLFQ. Mol Cell Proteomics 13:2513-2526. https://doi.org/10.1074/mcp.M113.031591

Cox J, Neuhauser N, Michalski A, et al (2011) Andromeda: A Peptide Search Engine Integrated into the MaxQuant Environment. J Proteome Res 10:17941805. https://doi.org/10.1021/pr101065j

de Gouvêa PF, Bernardi AV, Gerolamo LE, et al (2018) Transcriptome and secretome analysis of Aspergillus fumigatus in the presence of sugarcane bagasse. BMC Genomics 19:232. https://doi.org/10.1186/s12864-018-4627-8

de Lamo FJ, Constantin ME, Fresno DH, et al (2018) Xylem Sap Proteomics Reveals Distinct Differences Between R Gene- and Endophyte-Mediated Resistance Against Fusarium Wilt Disease in Tomato. Front Microbiol 9:. https://doi.org/10.3389/fmicb.2018.02977

Deng G-M, Yang Q-S, He W-D, et al (2015) Proteomic analysis of conidia germination in Fusarium oxysporum f. sp. cubense tropical race 4 reveals new targets in ergosterol biosynthesis pathway for controlling Fusarium wilt of banana. Appl Microbiol Biotechnol 99:7189-7207. https://doi.org/10.1007/s00253-015- 
$6768-x$

Dong H, Li Y, Fan H, et al (2019) Quantitative proteomics analysis reveals resistance differences of banana cultivar 'Brazilian' to Fusarium oxysporum f. sp. cubense races 1 and 4. J Proteomics 203:103376. https://doi.org/10.1016/j.jprot.2019.05.004

Fang X, Jost R, Finnegan PM, Barbetti MJ (2013) Comparative Proteome Analysis of the Strawberry-Fusarium oxysporum f. sp. fragariae Pathosystem Reveals Early Activation of Defense Responses as a Crucial Determinant of Host Resistance. J Proteome Res 12:1772-1788.

https://doi.org/10.1021/pr301117a

Ferrari S, Savatin DV, Sicilia F, et al (2013) Oligogalacturonides: plant damage-associated molecular patterns and regulators of growth and development. Front Plant Sci 4:. https://doi.org/10.3389/fpls.2013.00049

Gawehns F, Ma L, Bruning O, et al (2015) The effector repertoire of Fusarium oxysporum determines the tomato xylem proteome composition following infection. Front Plant Sci 6:. https://doi.org/10.3389/fpls.2015.00967

Gibson DM, King BC, Hayes ML, Bergstrom GC (2011) Plant pathogens as a source of diverse enzymes for lignocellulose digestion. Curr Opin Microbiol 14:264-270. https://doi.org/10.1016/j.mib.2011.04.002

Götz S, García-Gómez JM, Terol J, et al (2008) High-throughput functional annotation and data mining with the Blast2GO suite. Nucleic Acids Res 36:34203435. https://doi.org/10.1093/nar/gkn176

Hou X, An B, Wang Q, et al (2018) SGE1 is involved in conidiation and pathogenicity of Fusarium oxysporum f.sp. cubense. Can J Microbiol 64:349-357. https://doi.org/10.1139/cjm-2017-0638

Jiménez-Fernández D, Landa BB, Kang S, et al (2013) Quantitative and Microscopic Assessment of Compatible and Incompatible Interactions between Chickpea Cultivars and Fusarium oxysporum f. sp. ciceris Races. PLOS ONE 8:e61360. https://doi.org/10.1371/journal.pone.0061360

Kar B, Patel P, Ao J, Free SJ (2019) Neurospora crassa family GH72 glucanosyltransferases function to crosslink cell wall glycoprotein N-linked galactomannan to cell wall lichenin. Fungal Genet Biol 123:60-69. https://doi.org/10.1016/j.fgb.2018.11.007

Kubicek CP, Starr TL, Glass NL (2014) Plant Cell Wall-Degrading Enzymes and Their Secretion in Plant-Pathogenic Fungi. Annu Rev Phytopathol 52:427-451. https://doi.org/10.1146/annurev-phyto-102313-045831

Lagopodi AL, Ram AFJ, Lamers GEM, et al (2002) Novel Aspects of Tomato Root Colonization and Infection by Fusarium oxysporum f. sp. radicis-lycopersici Revealed by Confocal Laser Scanning Microscopic Analysis Using the Green Fluorescent Protein as a Marker. Mol Plant-Microbe Interactions ${ }^{\circledR} 15: 172-179$. https://doi.org/10.1094/MPMI.2002.15.2.172

Langner T, Öztürk M, Hartmann S, et al (2015) Chitinases Are Essential for Cell Separation in Ustilago maydis. Eukaryot Cell 14:846-857. https://doi.org/10.1128/EC.00022-15

Li E, Ling J, Wang G, et al (2015) Comparative Proteomics Analyses of Two Races of Fusarium oxysporum f. sp. conglutinans that Differ in Pathogenicity. Sci Rep 5:13663. https://doi.org/10.1038/srep13663

Li T, Wu Q, Wang Y, et al (2017) Application of Proteomics for the Investigation of the Effect of Initial pH on Pathogenic Mechanisms of Fusarium proliferatum on Banana Fruit. Front Microbiol 8:. https://doi.org/10.3389/fmicb.2017.02327

Li X, Bai T, Li Y, et al (2013) Proteomic analysis of Fusarium oxysporum f. sp. cubense tropical race 4-inoculated response to Fusarium wilts in the banana root cells. Proteome Sci 11:41. https://doi.org/10.1186/1477-5956-11-41

Lombard V, Golaconda Ramulu H, Drula E, et al (2014) The carbohydrate-active enzymes database (CAZy) in 2013. Nucleic Acids Res 42:D490-D495. https://doi.org/10.1093/nar/gkt1178

López-Mondéjar R, Catalano V, Kubicek CP, Seidl V (2009) The ß-N-acetylglucosaminidases NAG1 and NAG2 are essential for growth of Trichoderma atroviride on chitin. FEBS J 276:5137-5148. https://doi.org/10.1111/j.1742-4658.2009.07211.x

Lu Y, Liao D, Pu J, et al (2013) Proteome analysis of resistant and susceptible Cavendish banana roots following inoculation with Fusarium oxysporum f.sp. cubense. Physiol Mol Plant Pathol 84:163-171. https://doi.org/10.1016/j.pmpp.2013.09.002

Ma L-J, van der Does HC, Borkovich KA, et al (2010) Comparative genomics reveals mobile pathogenicity chromosomes in Fusarium. Nature 464:367-373. https://doi.org/10.1038/nature08850

Manikandan R, Harish S, Karthikeyan G, Raguchander T (2018) Comparative Proteomic Analysis of Different Isolates of Fusarium oxysporum f.sp. lycopersici to Exploit the Differentially Expressed Proteins Responsible for Virulence on Tomato Plants. Front Microbiol 9:. https://doi.org/10.3389/fmicb.2018.00420

Markovič O, Janeček Š (2001) Pectin degrading glycoside hydrolases of family 28: sequence-structural features, specificities and evolution. Protein Eng Des Sel 14:615-631. https://doi.org/10.1093/protein/14.9.615 
Millet N, Latgé J-P, Mouyna I (2018) Members of Glycosyl-Hydrolase Family 17 of A. fumigatus Differentially Affect Morphogenesis. J Fungi 4: https://doi.org/10.3390/jof4010018

Millet N, Moya-Nilges M, Sachse M, et al (2019) Aspergillus fumigatus exoß(1-3)glucanases family GH55 are essential for conidial cell wall morphogenesis. Cell Microbiol 21:e13102. https://doi.org/10.1111/cmi.13102

Miyauchi S, Navarro D, Grigoriev IV, et al (2016) Visual Comparative Omics of Fungi for Plant Biomass Deconstruction. Front Microbiol 7:. https://doi.org/10.3389/fmicb.2016.01335

Muschiol J, Vuillemin M, Meyer AS, Zeuner B (2020) B-N-Acetylhexosaminidases for Carbohydrate Synthesis via Trans-Glycosylation. Catalysts 10:365. https://doi.org/10.3390/catal10040365

Nitsche BM, Jørgensen TR, Akeroyd M, et al (2012) The carbon starvation response of Aspergillus niger during submerged cultivation: Insights from the transcriptome and secretome. BMC Genomics 13:380. https://doi.org/10.1186/1471-2164-13-380

Oyeleye A, Normi YM (2018) Chitinase: diversity, limitations, and trends in engineering for suitable applications. Biosci Rep 38:

https://doi.org/10.1042/BSR20180323

Paper JM, Scott-Craig JS, Adhikari ND, et al (2007) Comparative proteomics of extracellular proteins in vitro and in planta from the pathogenic fungus Fusarium graminearum. PROTEOMICS 7:3171-3183. https://doi.org/10.1002/pmic.200700184

Pelloux J, Rustérucci C, Mellerowicz EJ (2007) New insights into pectin methylesterase structure and function. Trends Plant Sci 12:267-277. https://doi.org/10.1016/j.tplants.2007.04.001

Petrasch S, Silva CJ, Mesquida-Pesci SD, et al (2019) Infection Strategies Deployed by Botrytis cinerea, Fusarium acuminatum, and Rhizopus stolonifer as a Function of Tomato Fruit Ripening Stage. Front Plant Sci 10:. https://doi.org/10.3389/fpls.2019.00223

Phalip V, Delalande F, Carapito C, et al (2005) Diversity of the exoproteome of Fusarium graminearum grown on plant cell wall. Curr Genet 48:366-379. https://doi.org/10.1007/s00294-005-0040-3

Pu Z, Ino Y, Kimura Y, et al (2016) Changes in the Proteome of Xylem Sap in Brassica oleracea in Response to Fusarium oxysporum Stress. Front Plant Sci 7:. https://doi.org/10.3389/fpls.2016.00031

Rast DM, Horsch M, Furter R, Gooday GW (1991) A complex chitinolytic system in exponentially growing mycelium of Mucor rouxii: properties and function. Microbiology, 137:2797-2810. https://doi.org/10.1099/00221287-137-12-2797

Raudvere U, Kolberg L, Kuzmin I, et al (2019) g:Profiler: a web server for functional enrichment analysis and conversions of gene lists (2019 update). Nucleic Acids Res 47:W191-W198. https://doi.org/10.1093/nar/gkz369

Rose JK, Saladié M, Catalá C (2004) The plot thickens: new perspectives of primary cell wall modification. Curr Opin Plant Biol 7:296-301. https://doi.org/10.1016/j.pbi.2004.03.013

Roy A, Jayaprakash A, T RR, et al (2020) Genome-wide annotation, comparison and functional genomics of carbohydrate-active enzymes in legumes infecting Fusarium oxysporum formae speciales. Mycology 11:56-70. https://doi.org/10.1080/21501203.2019.1706656

Ruiz E, Ruffner HP (2002) Immunodetection of Botrytis-specific Invertase in Infected Grapes. J Phytopathol 150:76-85. https://doi.org/10.1046/j.14390434.2002.00720.x

Schmidt SM, Houterman PM, Schreiver I, et al (2013) MITEs in the promoters of effector genes allow prediction of novel virulence genes in Fusarium oxysporum. BMC Genomics 14:119. https://doi.org/10.1186/1471-2164-14-119

Silva TD, Almeida CMA, Malafaia CB, et al (2017) Analysis of protein profile of tomato root infected with Fusarium oxysporum f. sp lycopersici. Genet Mol Res GMR 16:. https://doi.org/10.4238/gmr16027209

Sun Y, Yi X, Peng M, et al (2014) Proteomics of Fusarium oxysporum Race 1 and Race 4 Reveals Enzymes Involved in Carbohydrate Metabolism and lon Transport That Might Play Important Roles in Banana Fusarium Wilt. PLOS ONE 9:e113818. https://doi.org/10.1371/journal.pone.0113818

Szklarczyk D, Gable AL, Lyon D, et al (2019) STRING v11: protein-protein association networks with increased coverage, supporting functional discovery in genome-wide experimental datasets. Nucleic Acids Res 47:D607-D613. https://doi.org/10.1093/nar/gky1131

Tyanova S, Temu T, Cox J (2016a) The MaxQuant computational platform for mass spectrometry-based shotgun proteomics. Nat Protoc 11:2301-2319. https://doi.org/10.1038/nprot.2016.136

Tyanova S, Temu T, Sinitcyn P, et al (2016b) The Perseus computational platform for comprehensive analysis of (prote)omics data. Nat Methods 13:731-740. https://doi.org/10.1038/nmeth.3901 
Upasani ML, Gurjar GS, Kadoo NY, Gupta VS (2016) Dynamics of Colonization and Expression of Pathogenicity Related Genes in Fusarium oxysporum f.sp. ciceri during Chickpea Vascular Wilt Disease Progression. PLOS ONE 11:e0156490. https://doi.org/10.1371/journal.pone.0156490

van Dam P, Fokkens L, Ayukawa Y, et al (2017) A mobile pathogenicity chromosome in Fusarium oxysporum for infection of multiple cucurbit species. Sci Rep 7:9042. https://doi.org/10.1038/s41598-017-07995-y

Vlaardingerbroek I, Beerens B, Schmidt SM, et al (2016) Dispensable chromosomes in Fusarium oxysporum f. sp. lycopersici. Mol Plant Pathol 17:1455-1466. https://doi.org/10.1111/mpp. 12440

Voegele RT, Wirsel S, Möll U, et al (2006) Cloning and Characterization of a Novel Invertase from the Obligate Biotroph Uromyces fabae and Analysis of Expression Patterns of Host and Pathogen Invertases in the Course of Infection. Mol Plant-Microbe Interactions $\AA^{19: 625-634 . ~ h t t p s: / / d o i . o r g / 10.1094 / M P M I-~}$ $19-0625$

Williams AH, Sharma M, Thatcher LF, et al (2016) Comparative genomics and prediction of conditionally dispensable sequences in legume-infecting Fusarium oxysporum formae speciales facilitates identification of candidate effectors. BMC Genomics 17:191. https://doi.org/10.1186/s12864-016-2486-8

Wymelenberg AV, Gaskell J, Mozuch M, et al (2010) Comparative Transcriptome and Secretome Analysis of Wood Decay Fungi Postia placenta and Phanerochaete chrysosporium. Appl Environ Microbiol 76:3599-3610. https://doi.org/10.1128/AEM.00058-10

Yang S, Song S, Yan Q, et al (2014) Biochemical Characterization of the First Fungal Glycoside Hydrolyase Family 3 $\beta$-N-Acetylglucosaminidase from Rhizomucor miehei. J Agric Food Chem 62:5181-5190. https://doi.org/10.1021/jf500912b

Ye J, Zhang Y, Cui H, et al (2018) WEGO 2.0: a web tool for analyzing and plotting GO annotations, 2018 update. Nucleic Acids Res 46:W71-W75. https://doi.org/10.1093/nar/gky400

Zhang D, Meng KX, Hao YH, et al (2016) Comparative proteomic analysis of cucumber roots infected by Fusarium oxysporum f. sp. cucumerium Owen. Physiol Mol Plant Pathol 96:77-84. https://doi.org/10.1016/j.pmpp.2016.09.002

Zhang H, Yohe T, Huang L, et al (2018) dbCAN2: a meta server for automated carbohydrate-active enzyme annotation. Nucleic Acids Res 46:W95-W101. https://doi.org/10.1093/nar/gky418

\section{Tables}

Table 1. Number of proteins identified in the xylem sap proteomics data of susceptible tomato plant

\begin{tabular}{|lll|}
\hline & M & T \\
\hline Proteins after processing* & 473 & 413 \\
\hline Proteins identified in tomato & 473 & 360 \\
\hline Protein identified in Fol & 00 & 53 \\
\hline
\end{tabular}

(* removal of contaminant, reverse hits, identified by site and peptide count $<2$. These proteins were belonging to majority protein groups after processing in each experiment having four replicates were identified by the peptides present in more than two replicates)

Table 2. CAZymes annotation in the Fol proteins with their subcellular localization and presence/absence of secretory peptides. 


\begin{tabular}{|c|c|c|c|c|c|}
\hline Fol major protein groups accession & Gene id & Given Protein name & CAZymes & First activity in the family & $\begin{array}{l}\text { Signal } \\
\text { peptide }\end{array}$ \\
\hline XP_018247179.1; & FOXG_09774 & hypothetical protein & AA3_2 & glucose oxidase & OTHER \\
\hline \multicolumn{6}{|l|}{ XP_018247180.1 } \\
\hline XP_018253950.1 & FOXG_14236 & hypothetical protein & AA3_2 & glucose oxidase & $\mathrm{SP}(\mathrm{Sec} / \mathrm{SPI})$ \\
\hline XP_018253982.1 & FOXG_14258 & hypothetical protein & AA3_2 & glucose oxidase & $\mathrm{SP}(\mathrm{Sec} / \mathrm{SPI})$ \\
\hline XP_018246910.1 & FOXG_09570 & sialidase-1 & AA5_2 & galactose oxidase & $\mathrm{SP}(\mathrm{Sec} / \mathrm{SPI})$ \\
\hline XP_018250887.1 & FOXG_12330 & hypothetical protein & CE8 & pectin methylesterase & $\mathrm{SP}(\mathrm{Sec} / \mathrm{SPI})$ \\
\hline XP_018247509.1 & FOXG_10034 & hypothetical protein & GH18 & chitinase & $\mathrm{SP}(\mathrm{Sec} / \mathrm{SPI})$ \\
\hline XP_018248633.1;XP_018248634.1 & FOXG_10748 & chitinase & GH18 & chitinase & $\mathrm{SP}(\mathrm{Sec} / \mathrm{SPI})$ \\
\hline XP_018235878.1;XP_018235879.1;XP_018235880.1 & FOXG_02349 & beta-glucosidase & GH3 & $\beta$-glucosidase & $\mathrm{SP}(\mathrm{Sec} / \mathrm{SPI})$ \\
\hline XP_018250106.1 & FOXG_11736 & hypothetical protein & GH43_22 & $\beta$-xylosidase & $\mathrm{SP}(\mathrm{Sec} / \mathrm{SPI})$ \\
\hline XP_018254051.1 & FOXG_14489 & hypothetical protein & GH43_24 & $\beta$-xylosidase & $\mathrm{SP}(\mathrm{Sec} / \mathrm{SPI})$ \\
\hline XP_018235838.1; & FOXG_17741 & hypothetical protein & GH55 & $\beta-1,3$-glucanase & $\mathrm{SP}(\mathrm{Sec} / \mathrm{SPI})$ \\
\hline \multicolumn{6}{|l|}{ XP_018235839.1; } \\
\hline \multicolumn{6}{|l|}{ XP_018235840.1 } \\
\hline XP_018256212.1 & FOXG_15793 & hypothetical protein & GH93 & exo-a-L-1,5-arabinanase & $\mathrm{SP}(\mathrm{Sec} / \mathrm{SPI})$ \\
\hline XP_018231736.1; & FOXG_00102 & $\begin{array}{l}\text { beta-N- } \\
\text { acetvlhexosaminidase }\end{array}$ & $\mathrm{GH} 20$ & $\beta$-hexosaminidase & $\mathrm{SP}(\mathrm{Sec} / \mathrm{SPI})$ \\
\hline \multicolumn{6}{|l|}{ XP_018231737.1; } \\
\hline \multicolumn{6}{|l|}{ XP_018231738.1 } \\
\hline XP_018257975.1 & FOXG_17088 & hypothetical protein & GH28 & polygalacturonase & $\mathrm{SP}(\mathrm{Sec} / \mathrm{SPI})$ \\
\hline XP_018251964.1 & FOXG_12535 & hypothetical protein & $\mathrm{GH} 28$ & polygalacturonase & $\mathrm{SP}(\mathrm{Sec} / \mathrm{SPI})$ \\
\hline XP_018252069.1 & FOXG_12585 & hypothetical protein & GH28 & polygalacturonase & $\mathrm{SP}(\mathrm{Sec} / \mathrm{SPI})$ \\
\hline XP_018253513.1 & FOXG_14004 & polygalacturonase & $\mathrm{GH} 28$ & polygalacturonase & OTHER \\
\hline XP_018237179.1 & FOXG_03211 & $\begin{array}{l}\text { beta- } \\
\text { fructofuranosidase }\end{array}$ & GH32 & invertase & $\mathrm{SP}(\mathrm{Sec} / \mathrm{SPI})$ \\
\hline XP_018248486.1; & FOXG_10638 & endoglucanase type $K$ & GH45 & endoglucanase & OTHER \\
\hline \multicolumn{6}{|l|}{ XP_018248487.1 } \\
\hline XP_018250156.1 & FOXG_11769 & $\begin{array}{l}\text { mannosyl- } \\
\text { oligosaccharide }\end{array}$ & GH47 & a-mannosidase & $\mathrm{SP}(\mathrm{Sec} / \mathrm{SPI})$ \\
\hline
\end{tabular}

Page 10/16 
(Fol: Fusarium oxysporum f. sp. lycopersici, GH: Glycosyl hydrolase, AA: Auxillary activities, CE: Carbohydrate esterase)

(C:GO:0005576 - extracellular region; C:GO:0016020 - membrane; F:GO:0004553 - hydrolase activity, hydrolyzing 0-glycosyl compounds; F:GO:0004563 - betaN-acetylhexosaminidase activity; F:GO:0004571 - mannosyl-oligosaccharide 1,2-alpha-mannosidase activity; F:G0:0004650 - polygalacturonase activity; F:GO:0005509 - calcium ion binding; F:GO:0005515 - protein binding; F:GO:0008061 - chitin binding; F:GO:0008810 - cellulase activity; F:GO:0016614 oxidoreductase activity, acting on CH-OH group of donors; F:GO:0030248 - cellulose binding; F:G0:0030599 - pectinesterase activity; F:G0:0050660 - flavin adenine dinucleotide binding; P:G0:0005975 - carbohydrate metabolic process; P:GO:0005975 - carbohydrate metabolic process; P:G0:0042545 - cell wall modification; P:GO:0055114 - oxidation-reduction process)

Table 3. Chromosomal location of the accessions annotated for CAZymes

\begin{tabular}{|c|c|c|c|c|c|}
\hline Gene Accessions & CAZymes & Sequence accession & Chromosome & Length of sequence (base pairs) & Core/dispensable chromosome \\
\hline FOXG_09774 (F) & AA3 & \multirow[t]{3}{*}{ СM000599.1 } & \multirow[t]{3}{*}{11} & \multirow[t]{3}{*}{2337134} & \multirow[t]{3}{*}{ Core } \\
\hline FOXG_09570(R) & AA5 & & & & \\
\hline FOXG_10034 (R) & $\mathrm{GH} 18$ & & & & \\
\hline FOXG_12535 (F) & $\mathrm{GH} 28$ & \multirow[t]{2}{*}{ CM000591.1 } & \multirow[t]{2}{*}{3} & \multirow[t]{2}{*}{5634991} & \multirow[t]{2}{*}{ Core } \\
\hline FOXG_12585 (F) & $\mathrm{GH} 28$ & & & & \\
\hline FOXG_17741(F) & GH55 & \multirow[t]{2}{*}{ CM000593.1 } & \multirow[t]{2}{*}{5} & \multirow[t]{2}{*}{4914260} & \multirow[t]{2}{*}{ Core } \\
\hline FOXG_02349 (F) & $\mathrm{GH} 3$ & & & & \\
\hline FOXG_17088 (R) & $\mathrm{GH} 28$ & \multirow[t]{2}{*}{ CM000594.1 } & \multirow[t]{2}{*}{6} & \multirow[t]{2}{*}{4589937} & \multirow[t]{2}{*}{ Core } \\
\hline FOXG_14004 (R) & $\mathrm{GH} 28$ & & & & \\
\hline FOXG_10638 (R) & $\mathrm{GH} 45$ & \multirow[t]{2}{*}{ СM000595.1 } & \multirow[t]{2}{*}{7} & \multirow[t]{2}{*}{4347182} & \multirow[t]{2}{*}{ Core } \\
\hline FOXG_10748(F) & $\mathrm{GH} 18$ & & & & \\
\hline FOXG_03211 (R) & $\mathrm{GH} 32$ & \multirow[t]{2}{*}{ CM000596.1 } & \multirow[t]{2}{*}{8} & \multirow[t]{2}{*}{3984410} & \multirow[t]{2}{*}{ Core } \\
\hline FOXG_15793 (R) & GH93 & & & & \\
\hline FOXG_11769 (F) & $\mathrm{GH} 47$ & \multirow[t]{2}{*}{ CM000598.1 } & \multirow[t]{2}{*}{10} & \multirow[t]{2}{*}{2896840} & \multirow[t]{2}{*}{ Core } \\
\hline FOXG_11736 (R) & $\mathrm{GH} 43$ & & & & \\
\hline FOXG_14236 (F) & AA3_2 & \multirow[t]{2}{*}{ CM000602.2 } & \multirow[t]{2}{*}{14} & \multirow[t]{2}{*}{1838362} & \multirow[t]{2}{*}{ Dispensable } \\
\hline FOXG_14258 (F) & AA3_2 & & & & \\
\hline FOXG_00102 (R) & $\mathrm{GH} 20$ & СM000589.1 & 1 & 6854980 & Core \\
\hline FOXG_18811 (F) & $\mathrm{GH} 72$ & CM000592.1 & 4 & 5212762 & Core \\
\hline FOXG_14489 (R) & GH43_24 & CM000600.1 & 12 & 2233407 & Core \\
\hline FOXG_12330 (R) & CE8 & СM000601.1 & 13 & 1751499 & Core \\
\hline
\end{tabular}

(F: on forward strand; R: on reverse strand)

Table 4. Gene accessions for the CAZymes corresponding to the cluster of ortholog (COG), Eukaryotic ortholog (KOG) and non-supervised ortholog (NOG) 


\begin{tabular}{|c|c|c|c|c|c|c|c|}
\hline CAZymes & CAZymes name & Accession (Fol) & $\begin{array}{l}\text { Alias accession } \\
\text { (Fusarium } \\
\text { oxysporum) }\end{array}$ & $\begin{array}{l}\text { COG/KOG/NOG } \\
\text { accession }\end{array}$ & Description & $\begin{array}{l}\text { No. of } \\
\text { ortholog } \\
\text { proteins }\end{array}$ & $\begin{array}{l}\text { No. of } \\
\text { organisms }\end{array}$ \\
\hline AA3 & Glucose oxidase & $\begin{array}{l}\text { FOXG_09744; } \\
\text { FOXG_14236; } \\
\text { FOXG_14258 }\end{array}$ & $\begin{array}{l}\text { FOQG_11064; } \\
\text { FOQG_19211 }\end{array}$ & COG2303 & $\begin{array}{l}\text { Choline } \\
\text { dehydrogenase or } \\
\text { related flavoproteins }\end{array}$ & 13768 & 2812 \\
\hline CE8 & $\begin{array}{l}\text { Pectin methyl } \\
\text { esterase }\end{array}$ & FOXG_12330 & & COG4677 & $\begin{array}{l}\text { Pectin methyl esterase } \\
\text { and related acyl-coA } \\
\text { thioesterase }\end{array}$ & 5988 & 927 \\
\hline $\mathrm{GH} 3$ & $\beta$-glucosidase & FOXG_02349 & FOQG_08375 & COG1472 & $\begin{array}{l}\text { Periplasmic } \beta \text { - } \\
\text { glucosidase and } \\
\text { related glycosodase }\end{array}$ & 14784 & 3914 \\
\hline $\mathrm{GH} 18$ & Chitinase & $\begin{array}{l}\text { FOXG_10034; } \\
\text { FOXG_10748 }\end{array}$ & $\begin{array}{l}\text { FOQG_16748; } \\
\text { FOQG_17261 }\end{array}$ & COG3325 & $\begin{array}{l}\text { Chitinase, GH18 } \\
\text { family }\end{array}$ & 6649 & 1906 \\
\hline $\mathrm{GH} 20$ & $\beta$-hexosaminidase & FOXG_00102 & FOQG_07894 & COG3525 & $\begin{array}{l}\mathrm{N} \text {-acetyl } \beta \text { - } \\
\text { hexosaminidase }\end{array}$ & 5282 & 1906 \\
\hline $\mathrm{GH} 28$ & Polygalacturonase & $\begin{array}{l}\text { FOXG_12535; } \\
\text { FOXG_12585; } \\
\text { FOXG_14004; } \\
\text { FOXG_17088 }\end{array}$ & FOQG_19426 & COG5434 & Polygalacturonase & 9473 & 2060 \\
\hline $\mathrm{GH} 32$ & Invertase & FOXG_03211 & & NOG10950 & $\begin{array}{l}\text { GH family } 32 \mathrm{C} \\
\text { terminal }\end{array}$ & 22 & 18 \\
\hline $\mathrm{GH} 43$ & $\beta$-xylosidase & FOXG_11736 & FOQG_07578 & COG3940 & $\begin{array}{l}\beta-x y l o s i d a s e, ~ G H 43 \\
\text { family }\end{array}$ & 1425 & 754 \\
\hline GH47 & a- mannosidase & FOXG_11769 & FOQG_07554 & KOG2431 & $a-1,2-$ mannosidase & 873 & 426 \\
\hline GH55 & $\beta-1,3$-glucanase & FOXG_17741 & FOQG_08398 & NOG259137 & $\begin{array}{l}\text { Pectate lyase } \\
\text { superfamily }\end{array}$ & 286 & 122 \\
\hline
\end{tabular}

\section{Figures}



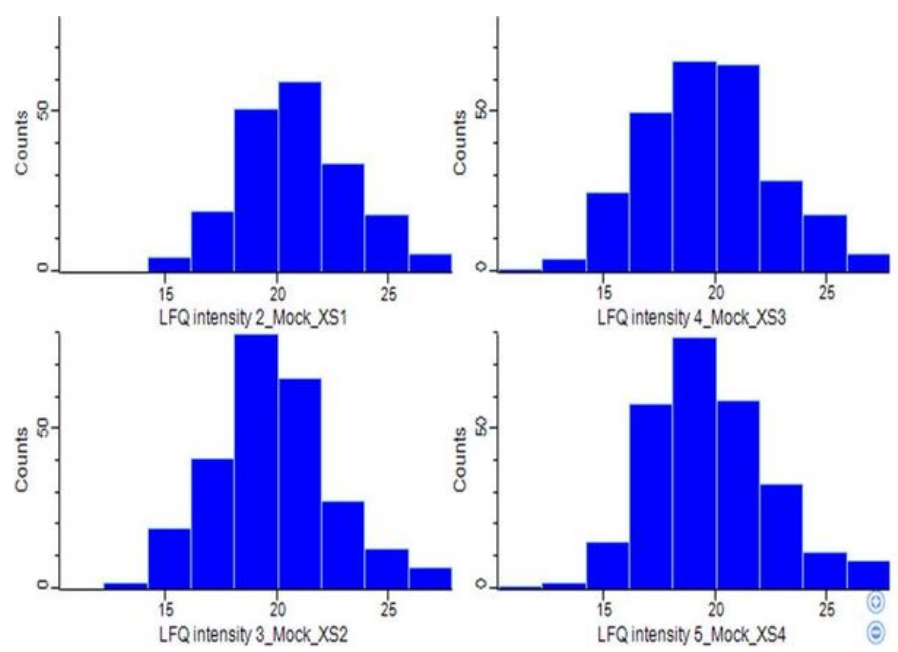

(a)
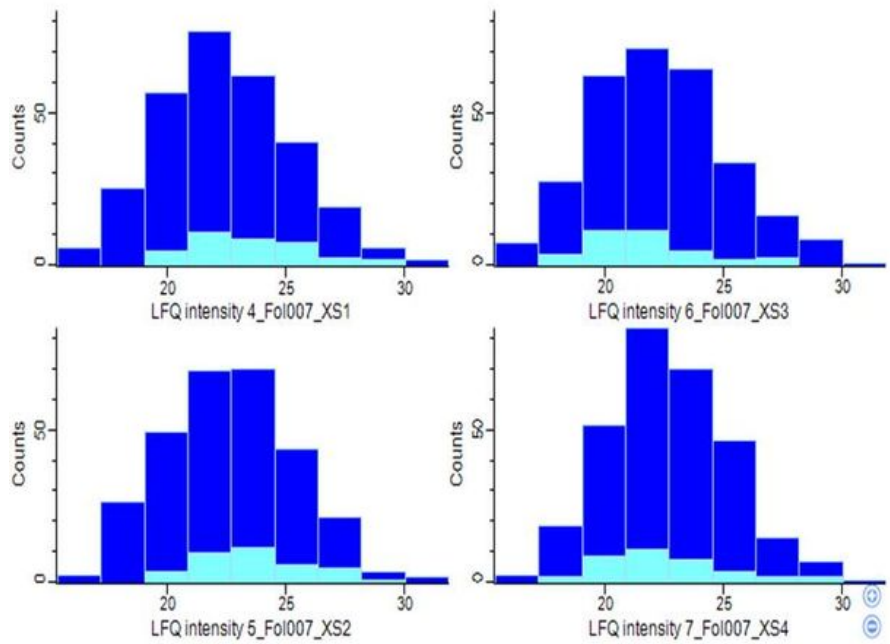
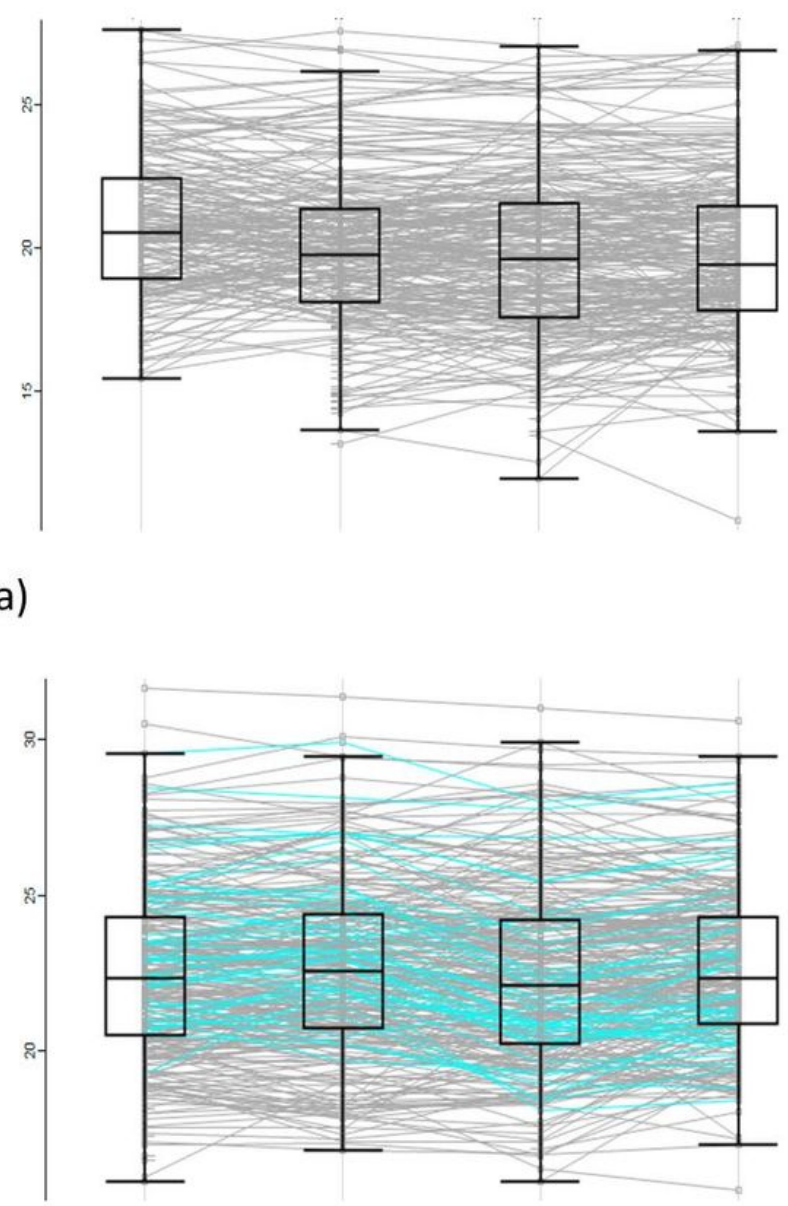

(b)

\section{Figure 1}

Histogram of $\log 2(x)$ transformed LFQ intensity (x-axis) vs. protein counts ( $y$-axis) and corresponding profile box plot of log2(x) transformed LFQ intensities, in the replicates of (a) Mock treated susceptible tomato variety C32 plant (control) (b) Fol007 (race 1) treated tomato cultivar C32 (treated). Light blue bars and lines are the LFQ intensities of the Fol proteins. (Fol: Fusarium oxysporum f. sp. lycopersici, LFQ: Label free quantification) 


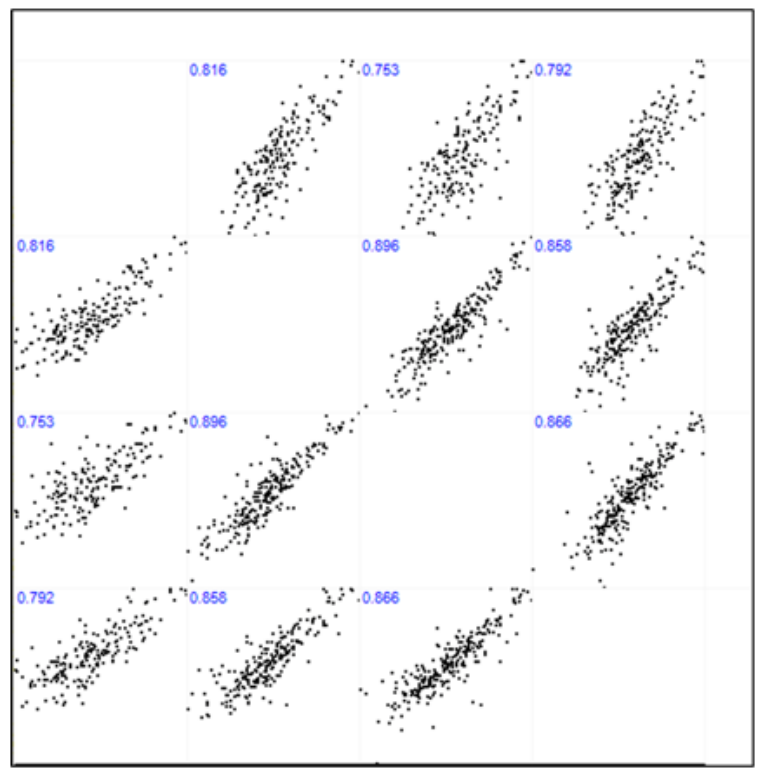

(a)

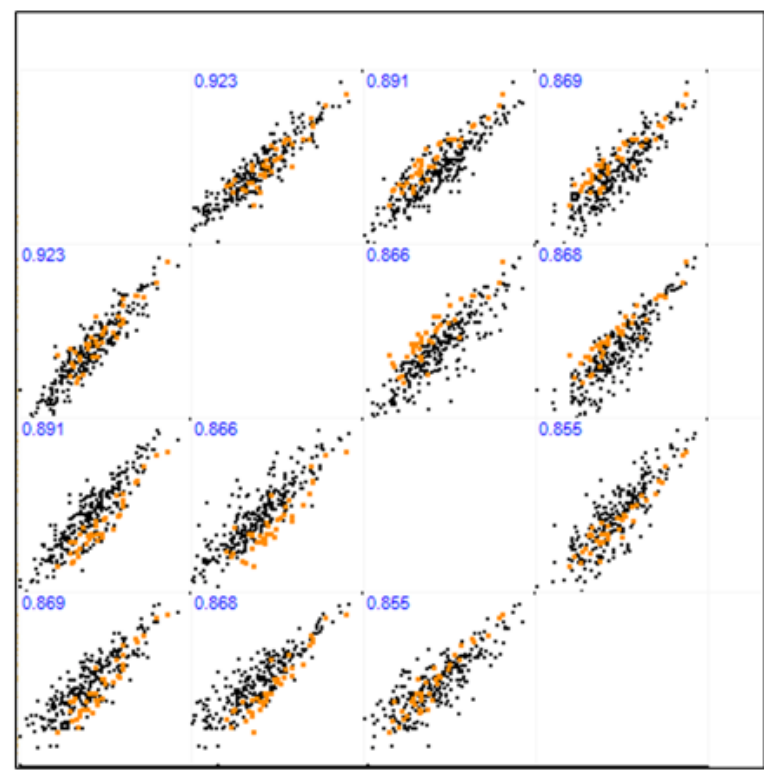

(b)

\section{Figure 2}

Multiple scatter plot of log2( $\mathrm{x}$ ) transformed LFQ intensities with Pearson correlation values above them in (a) Control, top to bottom from left to right each row: M1 vs. rest; M2 vs. rest; M3 vs. rest and M4 vs. rest (B) top to bottom from left to right each row: T1 vs. rest; T2 vs. rest; T3 vs. rest and T4 vs. rest

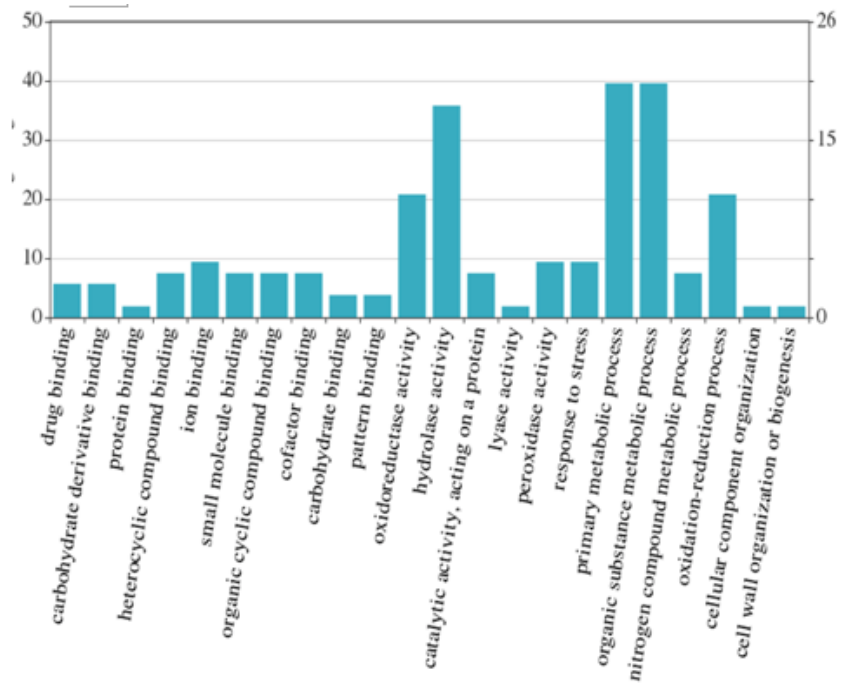

(a)

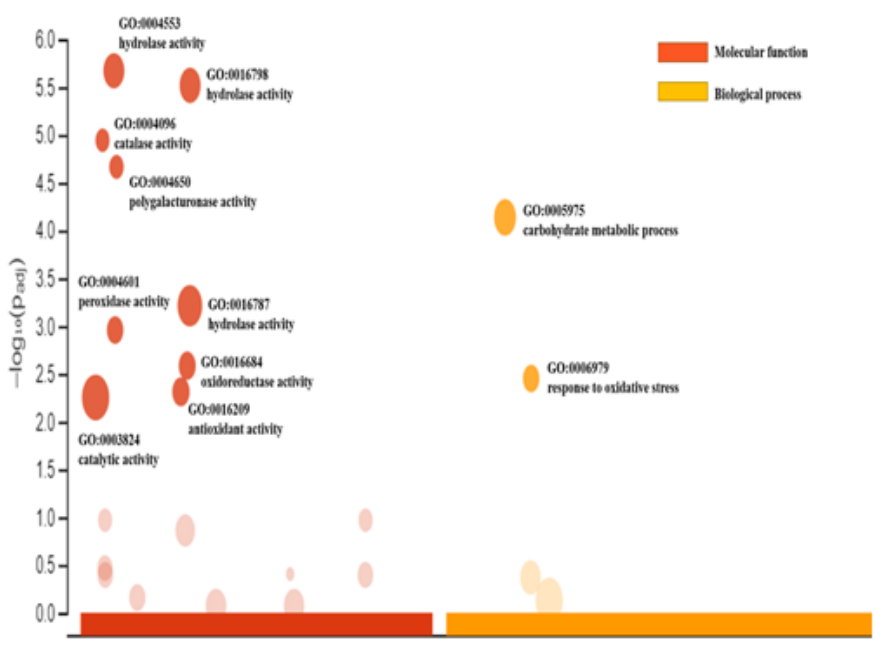

(b)

\section{Figure 3}

(a) Category-wise comparative plot of GO annotation of the identified proteins in the using WEGO online tool. ( $x$-axis: $G O$ categories with their functions, $y$-axis: percentage and number of proteins in each GO categories. (b) GO enrichment plot of gene accessions for identified Fol proteins. The circles which are darkened are significant molecular function (9) and biological process (2) in each experiments at padj <0.05 and (-log10 (padj) > 1.4. (padj: adjusted p-value) 


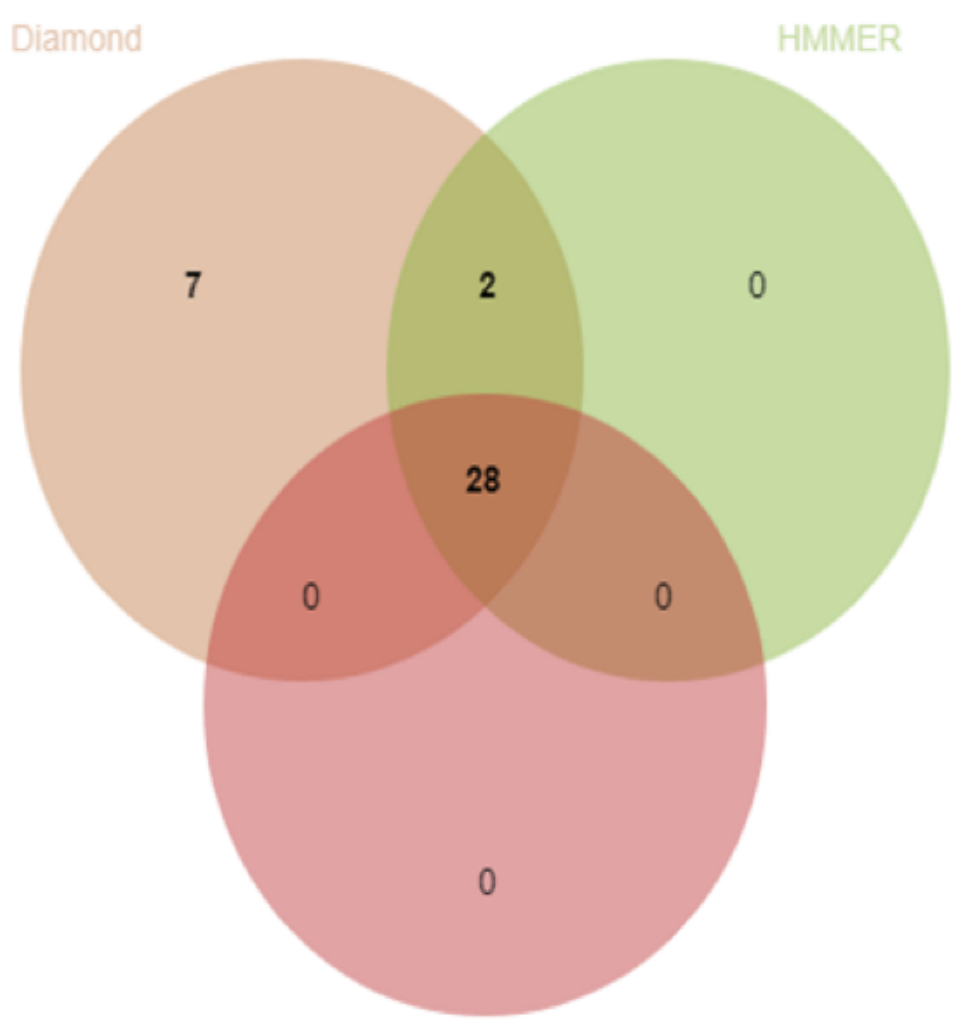

Hotpep

\section{Figure 4}

Venn diagram of annotated CAZymes. identified by Diamond, HMMER and HotPep, generated online through dbCAN2 annotation server with parameters: evalue $<1$ e-05 and query coverage of $>35 \%$ for HMMER, e-value $<1 \mathrm{e}-102$ for DIAMOND and frequency $>2.6$ for HotPep. 


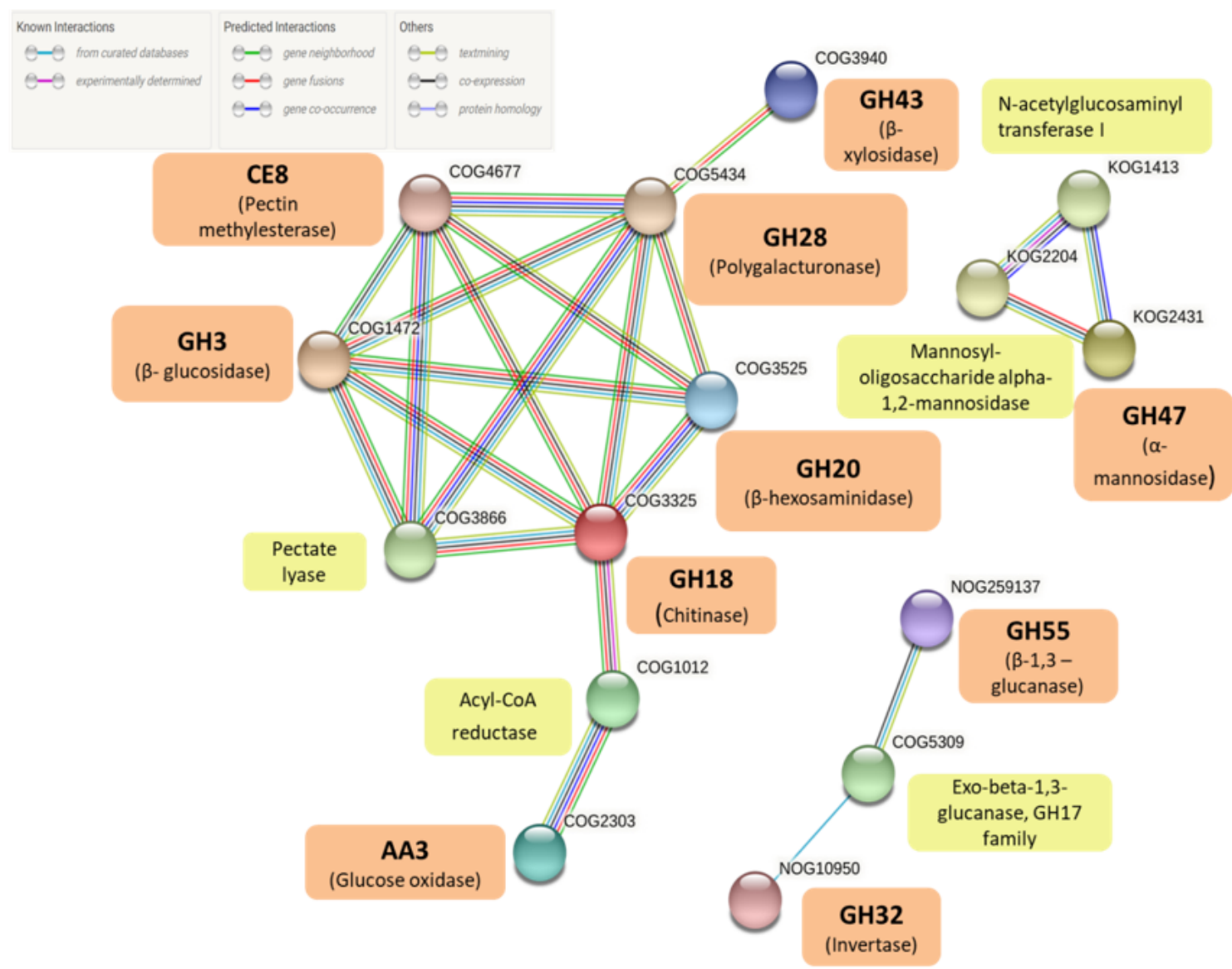

\section{Figure 5}

Ortholog interaction network of the identified core CAZymes. Encircled nodes are the direct interactional evidence of the core CAZymes families identified in Fol proteins. Nodes labelled in yellow are secondary interactions (i.e. first interactor shell) found in the database. The edges with different colors denoting the interaction evidence. (Fol: Fusarium oxysporum f. sp. lycopersici, AA: Auxillary activities; GH: Glycosyl hydrolases; CE: Carbohydrate esterase)

\section{Supplementary Files}

This is a list of supplementary files associated with this preprint. Click to download.

- graphicalabstract.jpg

- Supplememtarytables.docx 